\title{
A prospective study of absolute risk and determinants of human papillomavirus incidence among young women in Costa Rica
}

\author{
Megan Clarke ${ }^{1 *}$, Mark Schiffman ${ }^{1}$, Sholom Wacholder ${ }^{1}$, Ana Cecilia Rodriguez ${ }^{2}$, Allan Hildesheim ${ }^{1}$, Wim Quint $^{3}$
} and Costa Rican Vaccine Trial Group

\begin{abstract}
Background: High risk human papillomaviruses (HR-HPV) are known to be extremely common, sexually transmitted infections, but more information is needed regarding the absolute risks of type-specific HR-HPV infections in the years following sexual debut.

Methods: We conducted a survival analysis of 3,737 women aged 18-25 from the control group of the Costa Rican Vaccine trial to determine the absolute risks of HR-HPV infections at 12 months, 24 months, and end of follow-up (average of 50.7 months). To corroborate determinants of infection, we used Cox proportional hazards methods to assess associations between demographics and sexual risk behaviors and incident HR-HPV.

Results: Cumulative incidence for HR-HPV infections was $51.3 \%$ at the end of the study period. The most common incident types were HPV52 (15.4\%), HPV51 (13.6\%), and HPV16 (12.4\%). Type-specific cumulative incidence corresponded closely with type-specific prevalences, except that HPV16 was more prevalent than predicted by incidence, suggesting greater persistence. The strongest predictors of incident HR-HPV infections as a group in a multivariate analysis were the expected correlates of sexual behavior of the woman and her partner, such as being single (HR 1.6, 95\% Cl 1.4-1.8) or divorced/widowed (HR: 2.1, 95\% Cl: 1.7-2.7), having multiple HPV infections at enrollment (HR: 1.5, 95\% Cl: 1.3-1.7), and current smoking (HR: 1.2, 95\% Cl: 1.0-1.3). In women who reported being having only one lifetime sexual partner (being in a monogamous relationship), the strongest predictors of HR-HPV included not living with sex partner (HR: 2.1, 95\% Cl 1.7-2.5) and age of sex partner (HR: 1.4, 95\% Cl: 1.0-1.8).
\end{abstract}

Conclusion: We confirm the extremely high incidence of HR-HPV in young women, emphasizing the importance of vaccinating young girls before sexual debut.

Keywords: Human papillomavirus, Absolute risk, Risk factors, Sexual behavior

\section{Background}

Human papillomavirus (HPV) infections are easily transmitted by sexual contact and are very common among sexually active young women [1,2]. Approximately $90 \%$ of all HPV infections will clear (or become undetectable using standard methods) within a few years, yet a small proportion of persistent, carcinogenic HPV infections (HRHPV) will eventually cause cervical cancer if precancerous

\footnotetext{
*Correspondence: clarkma2@mail.nih.gov

'Division of Cancer Epidemiology and Genetics, National Cancer Institute, National Institutes of Health, DHHS, Bethesda, MD, USA

Full list of author information is available at the end of the article
}

lesions are not treated [3]. Currently, a prophylactic vaccine is available for HR-HPV types 16 and 18. The vaccine efficacy is high for types 16 and 18, and has also been shown to provide partial protection for types 31,33 , and 45 [4], yet other HR-HPV types are not known to be at all protected against by the vaccine. The absolute risks of acquiring individual cervical HR-HPV infection are not adequately defined; such analyses are surprisingly uncommon in the literature because they require large-scale HPV typing of sizable longitudinal studies.

The determinants of HPV infection acquisition, all types combined, are better defined. Risk for HPV acquisition is

\section{Ciomed Central}

(c) 2013 Clarke et al.; licensee BioMed Central Ltd. This is an Open Access article distributed under the terms of the Creative Commons Attribution License (http://creativecommons.org/licenses/by/2.0), which permits unrestricted use, distribution, and reproduction in any medium, provided the original work is properly cited. 
strongly associated with sexual behavior $[1,3,5]$. There is evidence to support that use of condoms and circumcision of the male partner reduces rates of HPV transmission [6,7].

Characterizing more fully the incidence of new HR-HPV infections in young sexually active women would be informative for models of HR-HPV transmission and vaccination impact. The Costa Rican Vaccine Trial (CVT) control arm provides an opportunity to study a large number of recently acquired HR-HPV infections within a group of young women aged 18-25 years old. Such a young and narrow age range enables us to look at the acquisition of new HR-HPV infections, presumably around the onset of sexual activity. The primary purpose of this study was to define the absolute risk of HR-HPV and typespecific HR-HPV infection in our cohort of young women. Secondarily, we wished to add to the already substantial literature on determinants of transmission. We were also interested in confirming or refuting our prior belief that different HPV types (e.g., high-risk vs. low-risk) have similar predictors.

\section{Methods}

\section{Study participants}

The study population consisted of all 3,739 women participating in the control group of the Costa Rican Vaccine Trial (CVT; NCT00128661)). Study design and procedures have been described elsewhere [8]. Briefly, CVT is a community-based, double-blind randomized phase III trial aimed at evaluating the efficacy of HPV 16/18 bivalent vaccine in preventing cervical precancers. At enrollment, women provided written informed consent. The trial recruited 7,466 women aged 18-25 years from the Guanacaste and Puntarenas provinces, Costa Rica. The vaccination schedule for both groups was three doses: one at enrollment, one month, and six months later. After receiving the vaccines, women were followed once per year for at least four years if their cytology was normal, and were transferred to a six-month follow-up schedule if they had HPV-related cytological abnormalities. We excluded women in the vaccine arm because we wanted to measure the true incidence and determinants of HR-HPV acquisition in an unvaccinated population.

All participants were administered an enrollment questionnaire by a trained interviewer. The questionnaire elicited information on level of education, marital status, household facilities, menstrual history, sexual, reproductive, and contraceptive history, smoking, and family history of cancer. Among women who reported being in a monogamous relationship, additional questions were asked about their sexual partner including their age, education, circumcision status, sexual history, and smoking history. All study protocols were reviewed and approved by the National Cancer Institute and Costa Rican Institutional Review Boards.

\section{HPV DNA testing}

Exfoliated cervical cells were collected using a Cervex brush and rinsed into a vial of $20 \mathrm{~mL}$ of PreservCyt solution during the pelvic exam. Samples were tested for HPV DNA by polymerase chain reaction (PCR) amplification with $\mathrm{SPF}_{10}$ primers followed by DNA enzyme immunoassay detection of amplimers. HPV typing on positive amplimers was performed using line probe assay $\left(\mathrm{LiPA}_{25}\right)$. All HPV positive samples that were HPV16/18 negative by $\mathrm{LiPA}_{25}$ were tested by type-specific PCR. Carcinogenic HPV types, termed high-risk HPV (HR-HPV) in this analysis, included 16,18,31,33,35,39,45,51,52,56,58, and 59 . Other HPV types, characterized as low-risk HPV (LR-HPV) included 6, $11,34,40,42,43,44,53,54,66,68,70,73,74$, and unknown types. The typing assay does not distinguish HPV68 and HPV73: they were included conservatively as low-risk.

\section{Statistical analysis}

For each individual HPV type, we estimated the 12 and 24 month and overall cumulative incidence. Incidence implied new detection of that HPV type for women who were or became sexually active who were completely HPV negative at enrollment or who were positive only for other types. Months at risk were calculated on the basis of number of months from the enrollment visit to detection of an incident HPV type or at the last followup visit, if a woman remained negative for that type throughout the study. Event times were calculated as the midpoint of the intervals between the last HPV type negative and the first HPV type positive visit.

Socio-demographic, sexual behavior, contraceptives, smoking and reproductive history characteristics measured at enrollment, as well as prevalent HPV infection and number of prevalent HPV types were evaluated as possible determinants of incident HR-HPV and LR-HPV infection. Continuous questionnaire variables were categorized based on trends in the data when appropriate. The five questions regarding household facilities were characterized as an overall measure of socioeconomic status (SES). Women who had all five household amenities (electricity, refrigerator, toilet, television, and running water) were considered to have high SES while women who had less than all five were categorized as low SES. The variable, years of sexual activity was calculated by subtracting the women's age at sexual debut from her age at enrollment. Questionnaire variables that only pertained to women having only one lifetime sexual partner were evaluated separately. From now on these women will be referred as being in "monogamous" relationships. 
Cox proportional hazards regression models were used to evaluate the relationship between enrollment questionnaire variables and time to incident HPV infection. Variables that were significant at the $p \leq 0.10$ level or below in the univariate analysis as well as those that were of particular interest for this study, (i.e. circumcision status and condom use) were considered in multivariate regression models. The final models included variables that were significant at the $\mathrm{p} \leq 0.05$ threshold and collinearity between covariates was assessed by calculating variance inflation factors for each variable after fitting the mulitvariable regression models. Two women were excluded for having a questionnaire that was deemed unreliable by the interviewer, leaving a total of 3,737 women in the final analysis. All analyses were conducted using STATA (version 11.0; StataCorp).

\section{Results}

\section{Prevalent and incident HR-HPV infections}

On average, women attended 4.476 screening follow-up visits throughout the study. Total person-months at risk was estimated to be 114,062.8 months for all HR-HPV types (data not shown). Table 1 shows the type-specific prevalence and cumulative incidence of HR-HPV, LR-HPV, and type-specific HR-HPV by time intervals, ending at the end of follow-up (averaging about 50 months for most women). HPV typing data was available for 3,731 women. At enrollment, 947 (25.3\%) women were HR-HPV positive and $812(21.8 \%)$ were LR-HPV positive. HPV16 was the most common prevalent type (7.1\%), followed by HPV52 and HPV51, respectively. Cumulative incidence

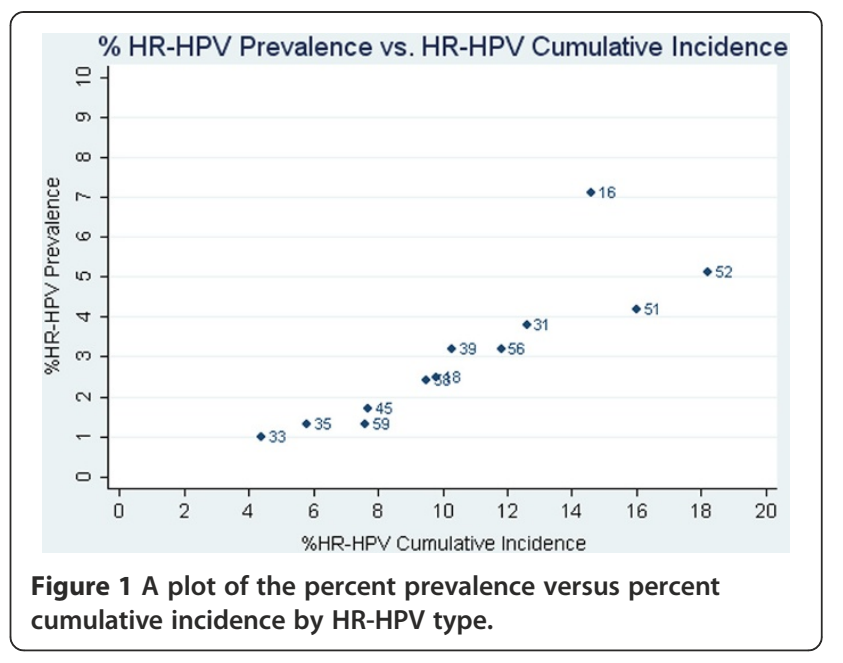

was slightly higher for LR-HPV types compared to HRHPV types (54.3\% vs. 51.3\%, respectively). Type-specific HR-HPV cumulative incidence varied, with HPV52 being the most common (15.4\%, 95\% CI: 14.3-16.7\%), followed by HPV51 (13.6\%, 12.5-14.7\%) and HPV16 (12.4\%, 11.413.5\%). Figure 1 shows a plot of type-specific HR-HPV prevalence versus cumulative incidence. A correlation was observed between the most common prevalent and incident types, with the exception of HPV16, which was highly prevalent compared to all other HR-HPV types, but had the third highest cumulative incidence. The cumulative incidence of multiple HR-HPV types was $32.9 \%$ (31.3$34.7 \%$ ) and a total of 1,022 women remained HPV negative throughout the entire study (data not shown).

Table 1 Prevalence and cumulative incidence of HR-HPV, LR-HPV, and HR-HPV types among 3,731 women in the Costa Rican Vaccine Trial

\begin{tabular}{|c|c|c|c|c|c|}
\hline & $\begin{array}{l}\text { \% HPV positive } \\
\text { at enrollment }\end{array}$ & $\begin{array}{l}\text { \% HPV negative } \\
\text { at enrollment }\end{array}$ & $\begin{array}{c}\text { \% Cumulative HPV } \\
\text { incidence" } 12 \text { months }\end{array}$ & $\begin{array}{l}\text { \% Cumulative HPV } \\
\text { incidence } 24 \text { months }\end{array}$ & $\begin{array}{c}\text { \% Cumulative HPV incidence } \\
\text { end of follow-up }\end{array}$ \\
\hline HR-HPV & 25.3 & 74.7 & 29.4 & 43.0 & 51.3 \\
\hline LR-HPV & 21.8 & 78.2 & 31.7 & 47.4 & 54.3 \\
\hline HPV16 & 7.1 & 92.9 & 5.7 & 9.8 & 12.4 \\
\hline HPV18 & 2.5 & 97.5 & 3.5 & 6.3 & 8.2 \\
\hline HPV31 & 3.8 & 96.2 & 4.7 & 8.0 & 10.5 \\
\hline HPV33 & 1.0 & 99.0 & 1.7 & 3.1 & 3.8 \\
\hline HPV35 & 1.3 & 98.7 & 2.4 & 3.6 & 4.8 \\
\hline HPV39 & 3.2 & 96.8 & 3.7 & 6.1 & 8.3 \\
\hline HPV45 & 1.7 & 98.3 & 3.0 & 5.3 & 6.5 \\
\hline HPV51 & 4.2 & 95.8 & 6.1 & 10.8 & 13.6 \\
\hline HPV52 & 5.1 & 94.9 & 6.3 & 12.1 & 15.4 \\
\hline HPV56 & 3.2 & 96.8 & 4.0 & 7.5 & 9.8 \\
\hline HPV58 & 2.4 & 97.6 & 3.6 & 6.0 & 7.8 \\
\hline HPV59 & 1.3 & 98.7 & 2.4 & 4.9 & 6.3 \\
\hline
\end{tabular}

\# Incidence defined by new detection of HPV type for women who were completely HPV negative at enrollment or who were positive only for other types. $\wedge$ Average end of follow-up is 50.7 months, very few women had a maximum end of follow-up of 76 months.

HR, High Risk; LR, Low Risk. 


\section{Univariate associations for risk of incident HR-HPV}

Table 2 presents the univariate associations for HR-HPV incidence among the 3,737 women included in this study. Within the restricted age range, age at enrollment was not related to HR-HPV acquisition. HR-HPV acquisition was significantly associated with being single or divorced/ widowed, high SES, not being a virgin at enrollment, not being in a monogamous relationship, fewer years since initiation of sexual activity, greater number of sex partners, and a history of cigarette smoking within the past six months. Lifetime OC use and lifetime injectable contraceptive use were protective against incident HR-HPV while history of condom use and use of barrier methods (both condoms and diaphragms) significantly increased the risk of HR-HPV acquisition. Being positive for any HPV type at enrollment significantly increased the risk of incident HR-

Table 2 Univariate cox proportional hazards regression analysis for incident HR-HPV among Women in the Costa Rican Vaccine Trial

\begin{tabular}{|c|c|c|c|c|c|c|}
\hline \multicolumn{2}{|l|}{ Woman characteristics } & \multicolumn{2}{|c|}{ Total } & \multicolumn{3}{|c|}{ Positive for one or more new HR-HPV type } \\
\hline & & $\mathrm{n}$ & Col \% & n & $\%$ & $\mathrm{HR}(95 \% \mathrm{Cl})$ \\
\hline \multirow[t]{2}{*}{ Age at Enrollment (years) } & $18-20$ & 1,729 & 46.4 & 864 & 50.0 & $1.1(1.0-1.2)$ \\
\hline & $21-25$ & 2,002 & 53.6 & 947 & 47.3 & Ref \\
\hline \multirow[t]{3}{*}{ Marital Status } & Divorced/Widowed & 98 & 2.6 & 70 & 71.4 & $2.5(1.9-3.1)$ \\
\hline & Single & 2,082 & 56.0 & 1,084 & 52.1 & $1.4(1.3-1.5)$ \\
\hline & Married or living as & 1,544 & 41.4 & 654 & 42.4 & Ref \\
\hline \multirow[t]{2}{*}{ Measures of SES } & All 5 & 3,012 & 80.7 & 1,517 & 50.4 & $1.3(1.2-1.5)$ \\
\hline & $<5$ & 719 & 19.3 & 294 & 40.9 & Ref \\
\hline \multirow[t]{2}{*}{ Virgin at Enrollment } & No & 2,918 & 78.2 & 1,543 & 52.9 & $2.0(1.7-2.2)$ \\
\hline & Yes & 813 & 21.8 & 268 & 33.0 & Ref \\
\hline \multirow[t]{4}{*}{ Years Sexually Active } & $<1-2$ & 674 & 23.1 & 393 & 58.3 & $1.4(1.2-1.7)$ \\
\hline & $3-4$ & 812 & 27.9 & 430 & 53.0 & $1.2(1.1-1.5)$ \\
\hline & $5-7$ & 890 & 30.6 & 461 & 51.8 & $1.1(1.0-1.3)$ \\
\hline & $>7$ & 536 & 18.4 & 256 & 47.8 & Ref \\
\hline \multirow[t]{2}{*}{ Monogamous Relationship } & No & 2,489 & 66.7 & 1,253 & 50.3 & $1.2(1.1-1.4)$ \\
\hline & Yes & 1,242 & 33.3 & 558 & 44.9 & Ref \\
\hline \multirow[t]{3}{*}{ Number of Sex Partners } & $3+$ & 902 & 31.2 & 560 & 62.1 & $1.7(1.5-1.9)$ \\
\hline & 2 & 749 & 25.9 & 408 & 54.5 & $1.4(1.2-1.6)$ \\
\hline & 1 & 1,242 & 42.9 & 558 & 44.9 & Ref \\
\hline \multirow[t]{3}{*}{ Duration Sexual Relationship with Partner (days) } & $1-330$ & 1,051 & 36.3 & 608 & 57.9 & $1.5(1.3-1.7)$ \\
\hline & $331-1200$ & 1,022 & 35.3 & 546 & 53.4 & $1.3(1.2-1.5)$ \\
\hline & $1201-4380$ & 824 & 28.4 & 376 & 45.6 & Ref \\
\hline \multirow[t]{2}{*}{ Lifetime Oral Contraceptive Use } & No & 562 & 20.0 & 360 & 64.1 & $1.5(1.3-1.7)$ \\
\hline & Yes & 2,255 & 80.0 & 1,124 & 49.8 & Ref \\
\hline \multirow[t]{2}{*}{ Lifetime Injectable Contraceptive Use } & No & 1,685 & 59.8 & 911 & 54.1 & $1.2(1.0-1.3)$ \\
\hline & Yes & 1,133 & 40.2 & 571 & 50.4 & Ref \\
\hline \multirow[t]{2}{*}{ Lifetime Condom Use } & Yes & 1,729 & 61.3 & 933 & 54.0 & $1.2(1.1-1.3)$ \\
\hline & No & 1,092 & 38.7 & 550 & 50.4 & Ref \\
\hline \multirow[t]{2}{*}{ Use of Barrier Methods During Sex } & Condom/Diaphragm & 788 & 27.1 & 465 & 59.0 & $1.3(1.2-1.4)$ \\
\hline & Neither & 2,123 & 72.9 & 1,074 & 50.6 & Ref \\
\hline \multirow[t]{2}{*}{ Smoked Cigarettes in Past 6 Months } & Yes & 499 & 13.4 & 317 & 63.5 & $1.7(1.5-1.9)$ \\
\hline & No & 3,225 & 86.6 & 1,491 & 46.2 & Ref \\
\hline \multirow[t]{2}{*}{ HPV Positive at Enrollment } & Yes & 1,459 & 39.1 & 902 & 61.8 & $2.0(1.8-2.2)$ \\
\hline & No & 2,272 & 60.9 & 909 & 40.0 & Ref \\
\hline \multirow[t]{3}{*}{ Number of Enrollment HPV Infections } & 2 or more types & 549 & 14.7 & 361 & 65.8 & $2.3(2.0-2.6)$ \\
\hline & 1 type & 910 & 24.4 & 541 & 59.5 & $1.9(1.7-2.1)$ \\
\hline & 0 types & 2,272 & 60.9 & 909 & 40.0 & Ref \\
\hline
\end{tabular}


HPV infection, as did being infected with more than one HPV type. We assessed whether history of condom use was confounded by increased frequency of sexual activity and found that risk of HR-HPV was no longer associated with condom use when adjusting for number of sexual partners. To determine whether being single or divorced was a proxy for more sexual relationships, we stratified the analysis of marital status by whether a woman was in a monogamous relationship. However, the hazard ratios (HR) were similar for women who were not in a monogamous relationship (single: HR: 1.1, 95\% CI: 1.0-1.3 and divorced: HR: 2.0, 95\% CI: 1.5-2.6) and women who were in a monogamous relationship (single: HR: 1.9, 95\% CI: 1.6-2.1 and divorced: HR 2.0, 95\% CI: 1.5-2.7). We observed very similar univariate associations for LR-HPV types (data not shown).

Among women who were in monogamous relationships (Table 3), younger age of sex partner, sex partner having had sexual intercourse with more than one other woman in their lifetime, not living with sex partner, and sex partner having a lifetime history of smoking were significantly associated with increased risk of incident HR-HPV infection. Male partner's circumcision status (reported by female partner) was not correlated with a decreased risk of HR-HPV acquisition, although the response rate for this question was very low (about $1 / 3$ of participants). Similar associations were observed for LR-HPV types (data not shown).

\section{Multivariate analysis for risk of incident HR-HPV}

In the multivariate model shown in Table 4, after controlling for age at enrollment, significant associations for acquisition of a new HR-HPV type included being single or divorced/widowed, high SES, shortest time since initiation of sexual activity ( $<1-2$ years), not being in a monogamous relationship, never using birth control pills, history of cigarette smoking within the past six months, and being positive for one or more HPV infections at enrollment. For LR-HPV types, only marital status and number of enrollment HPV infections were significant in the multivariate model (data not shown). Among women in monogamous relationships, not living with your sex partner, young age of sex partner, partner's lifetime history of smoking, and sex partner having intercourse with two or more other women were significantly associated with increased risk of incident HR-HPV. Similar associations were observed for LR-HPV types, with the exception of age of sex partner which was not included in the model (data not shown).

\section{Risks for the three most prevalent and incident HR-HPV types: 16,51 , and 52}

To determine if infection with the three most prevalent HR-HPV types influenced the subsequent incidence of other HR-HPV types, we conducted a Cox proportional hazard analysis in which prevalent infection with HPV16, HPV52, or HPV51 was used as a predictor of incident infection with other HR-HPV types. As predicted, we found that risk of incident HR-HPV infection of any type significantly increased if a woman was positive for HPV16, HPV52, or HPV51 at enrollment (data not shown).

In the univariate analysis of risk factors for HR-HPV incidence, we observed similar associations for HPV16, HPV51, and HPV52 to all HR-HPV types.

\section{Discussion}

Our study confirms the high incidence of HR-HPV among sexually active young women. HPV16 was the most common prevalent type at study enrollment and HPV52 was the most frequently detected incident type, followed by HPV51 and HPV16. A graphical representation of prevalent

Table 3 Univariate cox proportional hazards regression analysis for incident HR-HPV among women in monogamous relationships in the Costa Rican Vaccine Trial

\begin{tabular}{|c|c|c|c|c|c|c|}
\hline \multirow[b]{2}{*}{ Woman characteristics } & & \multicolumn{2}{|c|}{ Total } & \multicolumn{3}{|c|}{ Positive for one or more new HR-HPV types } \\
\hline & & $\mathbf{N}$ & Col (\%) & $\mathbf{N}$ & $\%$ & $\mathrm{HR}(95 \% \mathrm{Cl})$ \\
\hline \multirow[t]{3}{*}{ Age of Sex Partner (years) } & $16-24$ & 542 & 43.8 & 268 & 49.5 & $1.4(1.1-1.8)$ \\
\hline & $25-30$ & 483 & 39.1 & 207 & 42.9 & $1.1(0.9-1.5)$ \\
\hline & $>30$ & 212 & 17.1 & 80 & 37.7 & Ref \\
\hline \multirow[t]{3}{*}{ Number of Other Women Sex Partner has had Sex with } & $2+$ & 467 & 47.6 & 228 & 48.8 & $1.2(1.0-1.6)$ \\
\hline & 1 & 271 & 27.6 & 109 & 40.2 & $1.0(0.7-1.3)$ \\
\hline & 0 & 243 & 24.8 & 104 & 42.8 & Ref \\
\hline \multirow[t]{2}{*}{ Lives with Sex Partner } & No & 458 & 36.9 & 270 & 59.0 & $2.1(1.8-2.5)$ \\
\hline & Yes & 784 & 63.1 & 288 & 36.7 & Ref \\
\hline \multirow[t]{2}{*}{ Partner is Circumcised } & Yes & 604 & 52.9 & 267 & 44.2 & $1.0(0.9-1.2)$ \\
\hline & No & 538 & 47.1 & 241 & 44.8 & Ref \\
\hline \multirow[t]{2}{*}{ Sex Partner Ever Smoke } & Yes & 355 & 28.6 & 188 & 53.0 & $1.3(1.1-1.6)$ \\
\hline & No & 886 & 71.4 & 370 & 41.8 & Ref \\
\hline
\end{tabular}


Table 4 Multivariate cox proportional hazards regression analysis for risk of incident HR-HPV among all women and women in monogamous relationships in the Costa Rican Vaccine Trial

\begin{tabular}{|c|c|c|}
\hline \multicolumn{3}{|c|}{ All women } \\
\hline Women characteristics & & $\mathrm{HR}(95 \% \mathrm{Cl})$ \\
\hline \multirow[t]{3}{*}{ Marital Status } & Married & Ref \\
\hline & Single & $1.7(1.4-1.8)$ \\
\hline & Divorced/Widowed & $2.1(1.7-2.7)$ \\
\hline \multirow[t]{2}{*}{ Measures of SES } & Less than 5 & Ref \\
\hline & All 5 & $1.2(1.0-1.4)$ \\
\hline \multirow[t]{4}{*}{ Years Sexually Active } & $0-2$ & $1.3(1.1-1.6)$ \\
\hline & $3-4$ & $1.2(1.0-1.4)$ \\
\hline & $5-7$ & $1.1(1.0-1.3)$ \\
\hline & $>7$ & Ref \\
\hline \multirow[t]{2}{*}{ Monogamous Relationship } & Yes & Ref \\
\hline & No & $1.4(1.2-1.6)$ \\
\hline \multirow[t]{2}{*}{ Lifetime Oral Contraceptive Use } & Yes & Ref \\
\hline & No & $1.2(1.0-1.3)$ \\
\hline \multirow[t]{2}{*}{ Smoked Cigarettes Past 6 Months } & No & Ref \\
\hline & Yes & $1.2(1.0-1.4)$ \\
\hline \multirow[t]{3}{*}{ Number of Enrollment HPV Types } & 0 & Ref \\
\hline & 1 & $1.4(1.3-1.6)$ \\
\hline & $2+$ & $1.5(1.3-1.7)$ \\
\hline \multicolumn{3}{|c|}{ Women in Monogamous Relationships Only } \\
\hline \multirow[t]{2}{*}{ Lives with Sex Partner } & Yes & Ref \\
\hline & No & $2.1(1.7-2.5)$ \\
\hline \multirow[t]{3}{*}{ Age of Sex Partner (years) } & $16-24$ & $1.4(1.0-1.9)$ \\
\hline & $25-30$ & $1.4(1.0-1.8)$ \\
\hline & $>30$ & Ref \\
\hline \multirow[t]{2}{*}{ Sex Partner Ever Smoke } & No & Ref \\
\hline & Yes & $1.3(1.1-1.6)$ \\
\hline \multirow[t]{3}{*}{ Number of Other Women Sex Partner has had Sex with } & 0 & Ref \\
\hline & 1 & $1.0(0.8-1.3)$ \\
\hline & $2+$ & $1.3(1.0-1.6)$ \\
\hline
\end{tabular}

and incident HPV types confirms a correlation between frequency of prevalent types and incident types, with the exception of HPV16. The high prevalence of HPV16 relative to its incidence might suggest longer persistence. As expected, risk of incident HR-HPV infection was strongly influenced by variables related to sexual behavior. Both HR-HPV and LR-HPV had similar risk predictors for incident infection.

The high incidence rates we observed in our study are expected from a population of young sexually active women and are similar to other prospective studies of HPV incidence among young women in the United States, Denmark, Colombia, Brazil, and Canada [3,9-12]. Many of the risk factors for incident HR-HPV observed in this study have been reported elsewhere and confirm that risk of incident
HR-HPV infection is strongly influenced by sexual behavior $[1,3,9,13]$. High SES was associated with increased risk of HR-HPV. Some population-based surveys have reported that higher SES might sometimes be associated with a greater number of sexual partners, at least among males [14], though there are no data in the literature to suggest that high SES increases risk for HPV infection apart from a correlation with sexual behavior. The association between recent smoking history and partner's smoking history is also not well understood. In addition to our current findings, other studies that have shown a positive relationship between risk of HPV infection and smoking, suggesting it may be a proxy for high risk sexual behavior $[10,15,16]$. There is some, albeit inconsistent, evidence suggesting that smoking may influence 
the immune system [17]. Studies assessing the risk of incident HPV infection and OC use have also been inconsistent. Our findings indicate that lifetime $\mathrm{OC}$ use has a protective effect against HR-HPV acquisition and is in line with similar studies $[13,18]$, yet others report no association between OC use and incident HPV infection or even increased risk [19-22].

We did not find evidence suggesting that condom use was protective against HR-HPV acquisition, if anything our data shows an increased risk of HR-HPV infection with condom use, although this association was rendered insignificant when controlled for other measures of sexual behavior. There is conflicting data in the literature, several cross-sectional studies have shown that condom use by male partners does not reduce the risk of HPV infection in women [10], yet others suggest that consistent use of male condoms do effectively reduce the risk of HPV transmission [6]. Since in our study, condom use was a proxy for sexual activity, the modest association between increased HR-HPV and reported condom use might be explained by the fact that condoms are often not worn during every sexual act and even when worn, there could still be transmission.

We found no association between circumcision of male partners and reduced HR-HPV risk among women in monogamous relationships. The lack of association in our study could be due to reliance on the woman's report of her male partner's circumcision status, which may be unreliable. Furthermore, only one-third of the women included in this study responded to this this question, therefore the estimation of male partner's circumcision stats may have been inflated. Previous studies have shown that male circumcision is protective against HPV transmission from male to female partners [23,24]. However, a recent meta-analysis showed no association between male circumcision and HPV incidence among several pooled studies [25].

Limitations in our study included the fact that we were only able to use baseline questionnaire data and therefore were not able to evaluate associations between timedependent variables and risk of incident HR-HPV infection. Specifically, we did not have any follow-up information on a woman's sexual activity. Therefore, we do not know if women who reported being a virgin at enrollment, later became sexually active during the course of the study. This may bias our estimates of incidence, because we cannot determine whether these women are truly at risk. However, HPV is also transmissible through modes other than nonpenetrative sexual contact, and HPV has been detected among virgins in other studies [26,27]. The questionnaire was administered as an in-person interview during which participants may have been reluctant to disclose personal information regarding their sexual history resulting in potential response bias. For example, our assessment of condom use included broad categories such as "always" or "never" and was most likely an overestimation of condom use among women of reproductive age in Costa Rica [28]. Our estimation of male circumcision status was based on the woman's recall and a large proportion of women did not respond to this question, therefore this variable was highly subject to bias and misclassification, and probably reflects an overestimation of circumcision among Costa Rican men [29]. Our study had several strengths including the large number of women in our cohort and the narrow age range which allowed us to observe the early natural history of incident HPV infections among sexually active young women. The availability of HPV typing data allowed us to measure the cumulative risk for type-specific HR-HPV infections.

\section{Conclusions}

Our study provides good estimates of HR-HPV, LR-HPV, and type specific HR-HPV infections among a large cohort of sexually active young women. We have confirmed the sexually transmissible nature of HR-HPV infections and demonstrated a lack of association between condom use and female-reported, male partner circumcision status and HR-and LR-HPV acquisition. Other risks for HR-HPV infection included high socioeconomic status and smoking history, while lifetime use of birth control pills was protective for incident HR-HPV. Our findings demonstrate that HR-HPV is extremely common and underscore the importance of vaccinating young women before they become sexually active.

\section{Competing interests}

The authors declare that they have no competing interests. Vaccine was provided for our trial by GLAXOSMITHKLINE Biologicals, under a clinical trials agreement with NCI. GLAXOSMITHKLINE also provided support for aspects of the trial associated with the regulatory submission needs of the company. $\mathrm{NCl}$ and Costa Rican investigators make final editorial decisions on this publication; GLAXOSMITHKLINE has the right to review/comment. The funding agency did not have any involvement in the design of the study; the collection, analysis, and interpretation of the data; the writing of the article; or the decision to submit the article for publication.

\section{Authors' contributions}

MC: Analyzed data, drafted manuscript. MS: Involved in the conception and design of the study and provided critical revisions of manuscript. ACR: Made substantial contributions to conception and design of study and acquisition of data and provided critical review of the manuscript. SW: Biostatistician, involved in the design of the study and provided critical revisions of manuscript. $\mathrm{AH}$ : Made substantial contributions to conception and design of study and acquisition of data and provided critical review of the manuscript. All authors read and approved the final manuscript.

\section{Sources of support}

Intramural Research Program of the National Cancer Institute, National Institutes of Health. National Institutes of Health Office of Research on Women's Health.

The funding agency did not have any involvement in the design of the study; the collection, analysis, and interpretation of the data; the writing of the article; or the decision to submit the article for publication.

The Costa Rica HPV16/18 Vaccine Trial (NCT00128661) is a long-standing collaboration between investigators in Costa Rica and the National Cancer 
Institute $(\mathrm{NCl})$. The trial is funded by intramural $\mathrm{NCl}$ and the $\mathrm{NIH}$ Office of Research on Women's Health and is conducted in agreement with the Ministry of Health of Costa Rica. Vaccine was provided for our trial by GLAXOSMITHKLINE Biologicals, under a clinical trials agreement with NCI. The affiliations of the members of the Costa Rica HPV16/18 Vaccine Trial group are as follows. At the Proyecto Epidemiológico Guanacaste, Fundación INCIENSA, San José, Costa Rica: Mario Alfaro (Cytologist), Manuel Barrantes (Field Supervisor), M. Concepcion Bratti (Coinvestigator), Fernando Cárdenas (General Field Supervisor), Bernal Cortés (Specimen and Repository Manager), Albert Espinoza (Head, coding, and data entry), Yenory Estrada (Pharmacist), Paula Gonzalez (Coinvestigator), Diego Guillén (Pathologist), Rolando Herrero (Coprincipal Investigator), Silvia E. Jimenez (Trial Coordinator), Jorge Morales (Colposcopist), Lidia Ana Morera (Head Study Nurse), Elmer Pérez (Field Supervisor), Carolina Porras (Coinvestigator), Ana Cecilia Rodriguez (Coinvestigator), and Maricela Villegas (Clinic Physician); at the University of Costa Rica, San José, Costa Rica: Enrique Freer (Director, HPV Diagnostics Laboratory), Jose Bonilla (Head, HPV Immunology Laboratory), Sandra Silva (Head Technician, HPV Diagnostics Laboratory), Ivannia Atmella (Immunology Technician), and Margarita Ramírez (Immunology Technician); at the National Cancer Institute, Bethesda, MD: Nora Macklin (Trial Coordinator), Allan Hildesheim (Coprincipal Investigator and $\mathrm{NCl}$ Co-project Officer), Douglas R. Lowy (HPV Virologist), Mark Schiffman (Medical Monitor and NCI Co-project Officer), John T. Schiller (HPV Virologist), Mark Sherman (Quality Control Pathologist), Diane Solomon (Medical Monitor and Quality Control Pathologist), and Sholom Wacholder (Statistician); at SAIC, NCI—Frederick, Frederick, MD: Ligia Pinto (Head, HPV Immunology Laboratory) and Alfonso Garcia-Pineres (Scientist, HPV Immunology Laboratory); at Womens and Infants' Hospital, Providence, RI: Claire Eklund (Quality Control, cytology) and Martha Hutchinson (Quality Control, cytology); and DDL Diagnostics Laboratory, Voorburg, the Netherlands, Wim Quint (HPV DNA testing), and Leen-Jan van Doorn (HPV DNA testing), GLAXOSMITHKLINE Biologicals, Rixensart, Belgium Catherine Bougelet (HPV16/18 ELISA testing).

\section{Author details}

'Division of Cancer Epidemiology and Genetics, National Cancer Institute, National Institutes of Health, DHHS, Bethesda, MD, USA. ${ }^{2}$ Proyecto Epidemiológico Guanacaste, San José, Costa Rica. ${ }^{3}$ Delft Diagnostic Laboratories, Rijswijk, Netherlands.

\section{Received: 24 August 2012 Accepted: 25 June 2013}

Published: 8 July 2013

\section{References}

1. Winer RL, Feng Q, Hughes JP, O'Reilly S, Kiviat NB, Koutsky LA: Risk of female human papillomavirus acquisition associated with first male sex partner. J Infect Dis 2008, 197:279-282.

2. Burchell AN, Winer RL, de Sanjose S, Franco EL: Chapter 6: epidemiology and transmission dynamics of genital HPV infection. Vaccine 2006, 24(Suppl 3:S3):52-61

3. Ho GY, Bierman R, Beardsley L, Chang CJ, Burk RD: Natural history of cervicovaginal papillomavirus infection in young women. $N$ Engl J Med 1998, 338:423-428.

4. Kemp TJ, Hildesheim A, Safaeian M, Dauner JG, Pan Y, Porras C, Schiller JT, Lowy DR, Herrero R, Pinto LA: HPV16/18 L1 VLP vaccine induces cross-neutralizing antibodies that may mediate cross-protection. Vaccine 2011, 29:2011-2014

5. Burk RD, Ho GY, Beardsley L, Lempa M, Peters M, Bierman R: Sexual behavior and partner characteristics are the predominant risk factors for genital human papillomavirus infection in young women. J Infect Dis 1996, 174:679-689.

6. Winer RL, Hughes JP, Feng Q, O'Reilly S, Kiviat NB, Holmes KK, Koutsky LA: Condom use and the risk of genital human papillomavirus infection in young women. N Engl J Med 2006, 354:2645-2654

7. Wawer MJ, Tobian AA, Kigozi G, Kong X, Gravitt PE, Serwadda D, Nalugoda F, Makumbi F, Ssempiija V, Sewankambo N, et al: Effect of circumcision of HIV-negative men on transmission of human papillomavirus to HIV-negative women: a randomised trial in rakai, uganda. Lancet 2011, 377:209-218.

8. Herrero R, Hildesheim A, Rodriguez AC, Wacholder S, Bratti C, Solomon D, Gonzalez P, Porras C, Jimenez S, Guillen D, et al: Rationale and design of a community-based double-blind randomized clinical trial of an HPV 16 and 18 vaccine in guanacaste, costa rica. Vaccine 2008, 26:4795-4808.

9. Giuliano AR, Harris R, Sedjo RL, Baldwin S, Roe D, Papenfuss MR, Abrahamsen M, Inserra P, Olvera S, Hatch K: Incidence, prevalence, and clearance of type-specific human papillomavirus infections: the young Women's health study. J Infect Dis 2002, 186:462-469.

10. Nielsen A, Iftner T, Munk C, Kjaer SK: Acquisition of high-risk human papillomavirus infection in a population-based cohort of danish women. Sex Transm Dis 2009, 36:609-615.

11. Muñoz N, Méndez F, Posso H, Molano M, Van Den Brule AJC, Ronderos M, Meijer C, Muñoz Á: Incidence, duration, and determinants of cervical human papillomavirus infection in a cohort of colombian women with normal cytological results. J Infect Dis 2004, 190:2077-2087.

12. Franco EL, Villa LL, Sobrinho JP, Prado JM, Rousseau MC, Désy M, Rohan TE: Epidemiology of acquisition and clearance of cervical human papillomavirus infection in women from a high-risk area for cervical cancer. J Infect Dis 1999, 180:1415-1423.

13. Moscicki AB, Hills N, Shiboski S, Powell K, Jay N, Hanson E, Miller S, Clayton L, Farhat S, Broering J, et al: Risks for incident human papillomavirus infection and low-grade squamous intraepithelial lesion development in young females. JAMA 2001, 285:2995-3002.

14. de Sanjose S, Bosch FX, Munoz N, Shah K: Social differences in sexual behaviour and cervical cancer. IARC Sci Pub/ 1997:309-317.

15. Ferreccio C, Prado RB, Luzoro AV, Ampuero SL, Snijders PJ, Meijer CJ, Vaccarella SV, Jara AT, Puschel KI, Robles SC, et al: Population-based prevalence and age distribution of human papillomavirus among women in santiago, chile. Cancer Epidemiol Biomarkers Prev 2004, 13:2271-2276.

16. Chan PK, Chang AR, Cheung JL, Chan DP, Xu LY, Tang NL, Cheng AF: Determinants of cervical human papillomavirus infection: differences between high- and low-oncogenic risk types. J Infect Dis 2002, 185:28-35.

17. Sopori M: Effects of cigarette smoke on the immune system. Nat Rev Immunol 2002, 2:372-377.

18. Goodman MT, Shvetsov YB, McDuffie K, Wilkens LR, Zhu X, Thompson PJ, Ning L, Killeen J, Kamemoto L, Hernandez BY: Prevalence, acquisition, and clearance of cervical human papillomavirus infection among women with normal cytology: hawaii human papillomavirus cohort study. Cancer Research 2008, 68:8813-8824.

19. Sellors JW, Karwalajtys TL, Kaczorowski J, Mahony JB, Lytwyn A, Chong S, Sparrow J, Lorincz A: Incidence, clearance and predictors of human papillomavirus infection in women. CMAJ 2003, 168:421-425.

20. Lazcano-Ponce E, Herrero R, Munoz N, Cruz A, Shah KV, Alonso P, Hernandez P, Salmeron J, Hernandez M: Epidemiology of HPV infection among mexican women with normal cervical cytology. Int J Cancer 2001, 91:412-420

21. Peyton CL, Gravitt PE, Hunt WC, Hundley RS, Zhao M, Apple RJ, Wheeler CM: Determinants of genital human papillomavirus detection in a US population. J Infect Dis 2001, 183:1554-1564.

22. Marks M, Gravitt PE, Gupta SB, Liaw KL, Tadesse A, Kim E, Phongnarisorn C, Wootipoom V, Yuenyao P, Vipupinyo C, et al: Combined oral contraceptive use increases HPV persistence but not new HPV detection in a cohort of women from thailand. J Infect Dis 2011, 204:1505-1513.

23. Tobian AA, Gray RH: Male foreskin and oncogenic human papillomavirus infection in men and their female partners. Future Microbiol 2011, 6:739-745.

24. Castellsague X, Bosch FX, Munoz N, Meijer CJ, Shah KV, de Sanjose S, Eluf-Neto J, Ngelangel CA, Chichareon S, Smith JS, et al: Male circumcision, penile human papillomavirus infection, and cervical cancer in female partners. N Engl J Med 2002, 346:1105-1112.

25. Albero G, Castellsague X, Giuliano AR, Bosch FX: Male circumcision and genital human papillomavirus: a systematic review and meta-analysis. Sex Transm Dis 2012, 39:104-113.

26. Rylander E, Ruusuvaara $\mathrm{L}$, Almstromer MW, et al: The absence of vaginal human papillomavirus 16 DNA in women who have not experienced sexual intercourse. Obstet Gynecol 1994, 83:735-737.

27. Winer RL, Lee S, Hughes JP, Adam DE, Kiviat NB, Koutsky LA: Genital human papillomavirus infection: incidence and risk factors in a cohort of female university students. Am J Epidemiol 2003, 157:218-226.

28. United Nations Department of Economic and Social Affairs Population Division: World contraceptive Use 2009. 2007. World Health Organization HIV/AIDS 
Department: Geneva, Switzerland. Available at http://www.un.org/esa/ population/publications/contraceptive2009/contracept2009_wallchart_front. pdf. Accessed February 20, 2013.

29. United Nations, Department of Economic and Social Affairs, Population Division (2009). World Contraceptive Use 2009 (POP/DB/CP/Rev2009). New York, NY.

doi:10.1186/1471-2334-13-308

Cite this article as: Clarke et al:: A prospective study of absolute risk and determinants of human papillomavirus incidence among young women in Costa Rica. BMC Infectious Diseases 2013 13:308.

\section{Submit your next manuscript to BioMed Central} and take full advantage of:

- Convenient online submission

- Thorough peer review

- No space constraints or color figure charges

- Immediate publication on acceptance

- Inclusion in PubMed, CAS, Scopus and Google Scholar

- Research which is freely available for redistribution 